\title{
RESEÑA
}

\section{Reorganización financiera en Asia y América Latina en el periodo de postcrisis}

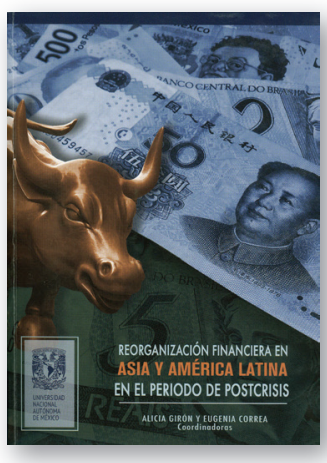

Reorganización financiera en Asia y América Latina en el periodo de postcrisis, Alicia Girón y Eugenia Correa (coordinadores), México, UNAM, Colección Universitaria de Estudios Asiáticos, vol. 5, 2017.

La crisis global financiera del año 2008 es considerada el acontecimiento causante de toda una reestructuración del sistema financiero y económico internacional, gracias a la complejidad de la interconexión de los mercados producida por la globalización entre todos los países del sistema internacional.

El mundo después de 2008 necesitó nuevas fórmulas para reestructurar el sistema financiero global. Para lograr dicho propósito, los análisis se orientaron a ciertas tendencias económicas: la formación de procesos de regionalización y segmentación financiera, así como la expansión de instrumentos financieros y no financieros estadounidenses, por ejemplo: los tratados involucrados con Asia. Sin embargo, las variables financiero-económicas no han resultado eficientes para entender el problema a fondo. La coyuntura política y los intereses detrás de los actores internacionales involucrados son elementos necesarios para la construcción de escenarios futuros.

Dentro de esa línea de investigación, esta publicación del Programa Universitario de Estudios sobre Asia y África ofrece una perspectiva sistemática de la reestructuración de las relaciones económicas y del modelo financiero internacional, en conjunto con la reconfiguración de las principales alianzas y bloques geopolíticos actuales.

1. Universidad Nacional Autónoma de México (UNAM), Facultad de Estudios Superiores Acatlán. Av. Alcanfores y San Juan Totoltepec s/n, Santa Cruz Acatlán, C.P. 53150, Naucalpan, Estado de México, México. ORCID: https://orcid.org/0000-0001-7718-4029. Correo electrónico: pao. berna@hotmail.com 
El libro Reorganización financiera en Asia y América Latina en el periodo de postcrisis está dividido en tres partes: 1) Reorganización en la postcrisis; 2) Acuerdo de Asociación Transpacífico (TPP, por sus siglas en inglés): integración y gobernabilidad económica, y 3) Segmentación y regionalización económica, monetaria y financiera.

En la primera parte se revisan los principales procesos de reorganización después de la crisis en Japón, China y América Latina, así como la disputa coyuntural por liderar el sistema financiero global entre Estados Unidos y la República Popular China. En el capítulo "Dólar versus yuan: competencia por la hegemonía", primeramente se hace un breve repaso de la hegemonía financiera del dólar y después se resaltan las ventajas económico-financieras del gigante asiático para considerarlo como posible sustituto del poder estadounidense. Bajo esa misma directriz, en el capítulo "China: la emergencia de una potencia financiera" se muestran las estrategias geoeconómicas implementadas por el país asiático para consolidar notoriamente un liderazgo económico y financiero global indiscutible, sin dejar a un lado los retos internos a los que se enfrentará a futuro.

En los últimos capítulos de esta primera sección se apunta a la conservación de la posición privilegiada de los arquitectos globales tradicionales, como en los casos de Brasil y Argentina, que son los países con más aproximaciones a China bajo los mandatos de izquierda. Bajo ese argumento, en "Estados Unidos y Unión Europea: recomposición geoestratégica mundial" se manifiesta la forma en que las instituciones financieras anglosajonas han buscado reafirmar su posición geoestratégica frente a la amenaza china, a través de herramientas geoeconómicas como el Tratado Transatlántico de Libre Comercio e Inversión entre Estados Unidos y la Unión Europea (TTIP, por sus siglas en inglés) y el Acuerdo de Asociación Transpacífico.

La segunda parte de la publicación está enfocada en mostrar diferentes perspectivas de análisis de la negociación del Acuerdo de Asociación Transpacífico (TTP), desde la formulación de las políticas monetarias, de salud y educación, hasta la implementación de las mismas en la administración pública. De igual forma, hace mención de las disputas geopolíticas entre Estados Unidos y China en la región del Pacífico.

En el primer capítulo, "Regionalización e integración: una respuesta a las consecuencias de la crisis financiera global", la autora profundiza en la explicación de la importancia de acuerdos como el TTP, resaltando la intención de formar instituciones supranacionales influenciadas por las empresas globales 
para proteger, en mayor medida, los intereses económicos estadounidenses en la región Asia-Pacífico.

Los siguientes capítulos invitan a entender la compatibilidad necesaria entre los países firmantes del TTP en cuestiones de políticas económicas, monetarias y cambiarias. En primer lugar, los autores hacen hincapié en mostrar a esta asociación como un acuerdo regional que involucra el comercio, la inversión y la expansión financiera, firmada por los gobiernos, quienes fungen como representantes de sus empresas transnacionales.

En esta sección destaca el texto "Expansión de la red de transportes en Asia", donde se realiza un análisis comparativo entre el тTP y la Nueva Ruta de la Seda, ambas estrategias estadounidenses y chinas (respectivamente) para expandir las redes de infraestructura en el continente asiático. Para finalizar este penúltimo apartado, la obra menciona la importancia de las decisiones regulatorias o de apertura gubernamentales de los Estados respecto a las compras públicas y las empresas de propiedad estatal.

En la tercera y última parte del libro, "Segmentación y regionalización económica, monetaria y financiera”, el objetivo es mostrar al lector cuáles son los bloques y alianzas geoeconómicas emergentes después de la crisis mundial, y cómo ha sido la reconstrucción de los procesos de financiarización y regionalización financiera en países latinoamericanos y asiáticos. Esta sección inicia con el análisis del Nuevo Banco de Desarrollo del bloque geoeconómico formado por Brasil, Rusia, India, China y Sudáfrica (BRICS), puntualizando su creciente proceso de institucionalización, aunque también se cuestiona la viabilidad de lograr conformar una alternativa al orden financiero mundial actual.

En los capítulos posteriores se revisa la expansión financiera asiática, orientada al sector minero en países de América Latina, y sus efectos en la reestructuración financiera de ambas regiones. Además, se examinan los procesos de regionalización financiera en los espacios bancarios de estas dos regiones con la ayuda de dos instrumentos económicos: el Mercado Común Centroamericano (MCCA) y la Asociación de Naciones del Sureste Asiático (ASEAN, por sus siglas en inglés).

Siguiendo el vínculo entre ambos continentes, resalta el estudio de la Alianza del Pacífico y sus relaciones con los gigantes asiáticos Corea, Japón y China, por la importancia geoeconómica de estos países para construir nuevos flujos de cooperación para la inserción en la economía global de los países latinoamericanos. Asimismo, se mencionan los factores causantes del crecimiento exponencial de la economía de India, gracias a los cuales las aso- 
ciaciones público-privadas han transformado la infraestructura de servicios sanitarios, de energía y de transporte en el territorio indio.

Finalmente, la publicación termina con un análisis comparativo de los modelos microfinancieros en Bangladesh y México, con el objetivo de mostrar las desventajas del modelo mexicano frente al asiático y los efectos atrasados en el combate contra la pobreza, debido a la corrupción en las instituciones financieras mexicanas.

El propósito de esta obra, que forma parte de la Colección Universitaria de Estudios Asiáticos de la UNAM, es mostrar al público los efectos de la crisis global financiera del año 2008 en la reconfiguración multipolar internacional, gracias a la participación de diferentes actores pertenecientes a América Latina y Asia. Las estrategias geoeconómicas de las potencias por mantener o aspirar al poder son cada vez más palpables, por lo que este libro cumple su meta al explicar los nuevos procesos de integración y cooperación financieroeconómica en estas regiones de una manera concisa. mị 